\title{
CHEMICAL COMPOSITION OF GALACTICAL PLANETARY NEBULAE
}

\author{
V. V. Holovatyy ${ }^{1}$, N. V. Havrylova ${ }^{2}$ \\ ${ }^{1}$ Department for Astrophysics and ${ }^{2}$ Astronomical Observatory, Ivan Franko National University of Lviv \\ 8 Kyryla and Mephodiya Str., UA-79005, Lviv, Ukraine
}

(Received February 25, 2002; received in final form March 18, 2003)

\begin{abstract}
This work starts the research of the chemical composition of planetary nebulae taking into account versatile inhomogeneities of gas density in planetary nebulae shells. We have determined the chemical composition of planetary nebulae using the radial distribution of gas density, which is close enough to the real distribution. The data for the chemical composition of 200 galactical planetary nebulae are presented. Abundances of He, C, N, O, Ne, Mg, Si, S and Ar are determined for a number of planetary nebulae 175, 64, 190, 200, 170, 13, 40, 173 and 187, respectively. Both the compositions for all 200 planetary nebulae and for photoionization models (to calculate ionizationcorrection factors) were obtained using the same method and the same atomic data. Observational data have been compiled from 105 papers published by other authors. The $Y-Z$ diagrams for combination of IIa,b planetary nebulae and the HII regions in the blue compact dwarf galaxies are analyzed. From the relation between $Y$ and $Z$, the primordial helium abundance $Y_{p}$ and the enrichment ratio $d Y / d Z$ are obtained. The radial abundance gradients in the galactic disk for He, $\mathrm{N}, \mathrm{O}, \mathrm{Ne}, \mathrm{S}$ and Ar are determined. The gradients obtained for these elements are somewhat lower in comparison with the data of other authors.
\end{abstract}

Key words: planetary nebulae, chemical abundance, primordial helium, abundance gradients.

PACS number(s): 98.38.Am, 98.38.Ly

\section{INTRODUCTION}

This article begins a comprehensive research of the chemical composition of planetary nebulae (PNs) taking into account versatile inhomogeneities of the gas density in PNs shells. Reliable determination of planetary nebulae composition is important for studying the stellar nucleosynthesis, history of star formation and peculiarities of chemical evolution of the matter in the Galaxy. Particularly, the PNs can be used for the determination of (i) the primordial helium abundance $Y_{p}$, (ii) the helium-tometal enrichment ratio $d Y / d Z$, and (iii) the radial abundance gradients in the galactic disk $d A / d D$, where $A$ is a chemical element and $D$ is a galactocentric distance. However, the results of the investigation of PNs chemical composition show that the available data are often ambiguous and sometimes even contradictory. We believe that the main reason of this lies in inaccuracy of the current methods for allowing for unobservable ionization stages of elements in PNs. So-called empirical relations, usually used for this purpose, are based only on the proximity of the ionization potentials of certain ions and they do not account for the differences in their effective photoionization cross sections and the excitation conditions of different spectral lines.

Obviously, the chemical composition of nebula can be most reliably determined by calculating a self-consistent photoionization model of the nebula luminosity. However, the calculation within such a model is a very laborious procedure. Moreover, it is impossible to calculate such models for many PNs due to the lack of appropriate observations. Therefore the usage of a photoionization model grid seems to be advisable for obtaining the correlations between the relative abundances of different ions. These correlations are used in order to take into account the unobservable stages of ionization. The principal results of this investigation are presented in this paper.

\section{DETERMINATION OF CHEMICAL COMPOSITION OF GALACTICAL PLANETARY NEBULA}

The method for determining the chemical composition of PNs is described by Golovatyi et. al. [1]. To consider unobservable stages of ionization, we have calculated a grid of photoionization models of PNs. The effective temperatures $T_{\text {eff }}$ and luminosities of the central stars correspond to the evolutionary tracks of Schönberner $[2,3]$ and Paczynski [4], and the spectra of the stars at $\lambda \leq$ 912 Acorrespond to the non-LTE models of the Clegg's and Middlemass' stellar atmospheres [5].

The nebular shell has been assumed to be spherically symmetrical. Note that this symmetry has been chosen to symplify our calculations. Obviously, a detailed study of the individual real objects requires for usage of asymmetry which is most close to the real one, including modelling of bipolar structure luminosity. Our method can be used to solve this task, so we plan to perform such calculations soon.

We decided to study the influence of gas density inhomogeneities on the determination of the PNs chemical composition. Unlike other authors, we used the radial distribution of gas density given by the empirical relation 


\section{V. HOLOVATYY, N. V. HAVRYLOVA}

$$
n(r)=\frac{x^{2}\left(1+3 e^{-1.2 x}\right)}{\left(x^{2}-1\right)+0.36 r_{c}^{-0.43} x^{2}} \frac{A}{r_{c}^{2}} \mathrm{~cm}^{-3},
$$

where $x=r / r_{c}$ and $r_{c}=\left\langle V_{\text {exp }}\right\rangle t$. Here $r$ is a distance from the central star to a particular point of nebula, $n$ is gas density at this point, $\left\langle V_{\text {exp }}\right\rangle$ is mean expansion velocity of the shell (nearly $15 \mathrm{~km} / \mathrm{s}$ ), and $t$ is shell age (the values of $r$ and $r_{c}$ in (1) are given in parsecs). Equation (1) was derived by Golovatyi et al. [1] by approximating the grid of surface brightness distributions for the PNs at different stages of evolution. The parameter $r_{c}$ characterizes the shell age, and the parameter $A$ is close to 1.6 for most of PNs with low-mass central stars and increases when the masses of stars increase. Every model was calculated for the solar chemical composition of gas. Then, the abundances were set up to be twice the solar ones, and then half of the solar abundances.

The integrated emission line spectrum of every calculated model was analyzed in the same way as the spectrum of a real PN is usually analyzed. We determined the electron density $n_{e}$ and electron temperature $T_{e}$ by the usual method for four luminosity/ionization zones: [OI], [OII], [OIII] and HeII. The values $n_{e}$ and $T_{e}$ were then used to determine the relative abundances of ions $A^{+i} / \mathrm{H}^{+}$in each zone. When analyzing the spectra, we used the same atomic data as those in the model calculations.

We considered the correlations between the quantities like $\log \left[\left(A^{+i} / \mathrm{H}^{+}\right) /(A / \mathrm{H})\right]$ and $\log \left(X^{+k+1} / X^{+k}\right)$, where $A / H$ denotes the abundance of a particular element $A, A^{+i} / \mathrm{H}^{+}$is the relative abundance of ions, and $X^{+k+1} / X^{+k}$ is that of the ratios $\mathrm{He}^{++} / \mathrm{He}^{+}, \mathrm{O}^{++} / \mathrm{O}^{+}$, $\mathrm{Ne}^{++} / \mathrm{Ne}^{+}, \mathrm{S}^{++} / \mathrm{S}^{+}, \mathrm{S}^{3+} / \mathrm{S}^{++}$, or $\mathrm{Ar}^{3+} / \mathrm{Ar}^{++}$(these ratios are also determined with analyzing the spectrum). We approximated these correlations by the least-squares technique using the analytical expressions for $f(x), \log \left[\left(A^{+i} / \mathrm{H}^{+}\right) /(A / \mathrm{H})\right]=f(x), x=$ $\log \left(X^{+k+i} / X^{+k}\right)$, enabling us to determine the abundance

$$
\log (A / \mathrm{H})=\log \left(A^{+i} / \mathrm{H}^{+}\right)-f(x)
$$

where the values of $f(x)$ are given by Golovatyi et. al. [1]. Depending on the correlation in different ranges of $X$, the functions $f(x)$ are represented either by parabolic or by linear approximating relations.

The important advantages of the proposed method for determining the chemical composition of PNs are as follows: (i) it uses a gas density distribution close to that of real PNs, and hence it allows for the stratification of physical conditions in a nebula, (ii) the derived correlations, similar to those from formula (2), use the ion abundances obtained in the same way as in investigations of real nebulae, i.e., by analyzing the spectrum, (iii) for every correlation, the method simulataneously allows to take into account all the stages of the element ionization.

We present the chemical composition of 200 galactic PNs. References for the observation data are available at the FTP server of the Astronomical Observatory of the Ivan Franko National University of Lviv at the following address: ftp://astro.franko.lviv.ua/pub/PNs/JPS/PNsList.ps

The abundances for all the PNs are obtained using the same atomic data and a method of abundance determination, so our database is highly homogeneous. A sample of these PNs, as well as their basic parameters and their abundances of He, C, N, O, Ne, $\mathrm{S}$ and $\mathrm{Ar}$ are listed in the table at the FTP server of the Astronomical Observatory of the Ivan Franko National University of Lviv at the following address: ftp://astro.franko.lviv.ua/pub/PNs/JPS/AllPNs.ps

This table contains data for the type of I PNs (bulge and galo population) and the type II PNs (disk population). The PNs of the types IIa and IIb differ by chemical composition of nitrogen. The next analysis involves the type II PNs and their compositions are presented in Table 1.

The comparison of our data for the IIa,b type PNs (see cols. 5-8, Table 1) with the corresponding data of Maciel and Köppen [6] is shown in Fig. 1.

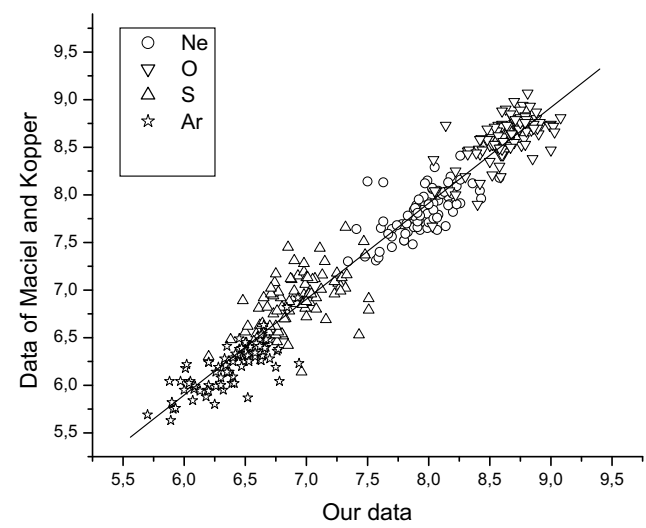

Fig. 1. Comparison of our data for the PNs chemical composition with the data of Maciel and Köppen (1994). 


\begin{tabular}{|c|c|c|c|c|c|c|c|c|c|c|c|}
\hline Nebula & $\mathrm{He} / \mathrm{H}$ & $\mathrm{C} / \mathrm{H}$ & $\mathrm{N} / \mathrm{H}$ & $\mathrm{O} / \mathrm{H}$ & $\mathrm{Ne} / \mathrm{H}$ & $\mathrm{S} / \mathrm{H}$ & $\mathrm{Ar} / \mathrm{H}$ & Type & $Z$ & $\bar{Y}$ & $\mathrm{D}, \mathrm{kpc}$ \\
\hline 1 & 2 & 3 & 4 & 5 & 6 & 7 & 8 & 9 & 10 & 11 & 12 \\
\hline NGC 40 & - & $05^{-}$ & $1.35^{-4}$ & $9.55^{-4}$ & $1.38^{-4}$ & $6.46^{-6}$ & $1.70^{-6}$ & IIa & .0229 & - & 8.48 \\
\hline NGC 650 & 0.110 & - & $2.51^{-4}$ & $5.75^{-4}$ & $1.10^{-4}$ & $1.18^{-5}$ & $2.19^{-6}$ & IIa & 0.0138 & 0.286 & 8.22 \\
\hline NGC 1535 & 0.091 & $1.91^{-4}$ & $3.80^{-5}$ & $3.89^{-4}$ & $5.37^{-5}$ & - & $1.05^{-6}$ & IIb & 0.00742 & 0.250 & 8.87 \\
\hline NGC 2022 & 0.105 & $5.01^{-4}$ & $18^{-4}$ & $3.02^{-4}$ & $6.46^{-5}$ & $1.41^{-5}$ & $1.78^{-6}$ & IIa & 0.00997 & 0.278 & 11.2 \\
\hline NGC 2242 & 105 & $1.12^{-4}$ & $5.89^{-6}$ & $4.68^{-5}$ & $3.31^{-5}$ & - & $4.27^{-7}$ & IIb & 0.00223 & 0.280 & 13.8 \\
\hline NGC 2371 & 0.115 & $6.46^{-4}$ & $1.48^{-4}$ & $5.37^{-4}$ & $1.02^{-4}$ & $2.04^{-5}$ & $2.82^{-6}$ & IIa & 0.0143 & 0.296 & 10.8 \\
\hline NGC 2392 & 091 & $8.91^{-5}$ & $1.29^{-4}$ & $2.24^{-4}$ & $3.31^{-5}$ & $8.32^{-6}$ & $7.59^{-6}$ & IIa & 0.00541 & 0.250 & 8.59 \\
\hline NGC 2438 & 0.110 & - & $1.44^{-4}$ & $4.79^{-4}$ & $6.61^{-5}$ & $1.29^{-5}$ & $2.19^{-6}$ & IIa & 0.0117 & 0.287 & 8.52 \\
\hline NGC 2452 & 0.112 & - & $1.86^{-4}$ & $5.50^{-4}$ & $7.76^{-5}$ & $1.55^{-5}$ & $2.51^{-6}$ & IIa & 0.0133 & 0.290 & 11.2 \\
\hline NGC 2867 & 0.102 & $1.38^{-}$ & $1.23^{-4}$ & $5.13^{-4}$ & $6.52^{-5}$ & $8.71^{-6}$ & $1.38^{-6}$ & IIa & 0.00936 & 0.272 & 8.28 \\
\hline NGC 3211 & 102 & - & - & $5.62^{-4}$ & $4.68^{-5}$ & $1.44^{-5}$ & $1.90^{-6}$ & IIb & 0.0135 & 0.271 & 7.51 \\
\hline NGC 3242 & 085 & $3.39^{-4}$ & $7.76^{-5}$ & $3.72^{-4}$ & $4.79^{-5}$ & $3.63^{-6}$ & $9.77^{-6}$ & IIb & 0.00904 & 0.236 & 8.08 \\
\hline NGC 3587 & 0.098 & - & $8.51^{-5}$ & $2.63^{-4}$ & $4.27^{-5}$ & $3.31^{-6}$ & $1.20^{-6}$ & IIa & 0.00684 & 0.265 & 8.14 \\
\hline NGC 3918 & 098 & - & $1.70^{-4}$ & $3.89^{-4}$ & $1.07^{-4}$ & $6.61^{-6}$ & $1.86^{-6}$ & IIa & 0966 & 0.264 & 7.27 \\
\hline NGC 4361 & 0.112 & $2.09^{-4}$ & - & $1.10^{-4}$ & $2.04^{-5}$ & - & $5.67^{-7} \mid$ & IIa & 0.00422 & 0.293 & 7.47 \\
\hline NGC 5315 & 110 & $2.57^{-4}$ & $2.46^{-4}$ & $4.68^{-4}$ & $1.18^{-4}$ & $1.10^{-5}$ & $3.02^{-6}$ & IIa & 16 & 0.287 & 6.10 \\
\hline NGC 5882 & 105 & $1.38^{-4}$ & $1.15^{-4}$ & $6.31^{-4}$ & $9.55^{-5}$ & $1.90^{-5}$ & $2.40^{-6}$ & IIa & 111 & 0.277 & 5.72 \\
\hline NGC 6153 & 0.112 & $1.38^{-3}$ & $2.09^{-4}$ & $1.17^{-3}$ & $2.57^{-4}$ & $2.75^{-5}$ & $4.27^{-6}$ & IIa & 0.0297 & 0.285 & 5.85 \\
\hline C 6309 & 0.112 & - & $2.04^{-4}$ & $5.25^{-4}$ & $8.71^{-5}$ & $1.05^{-5}$ & $2.29^{-6}$ & IIa & 27 & 0.290 & 4.48 \\
\hline NGC 6326 & 0.112 & - & $1.62^{-4}$ & $6.91^{-4}$ & $1.10^{-4}$ & $1.07^{-5}$ & $1.55^{-6}$ & IIa & 0.0164 & 0.289 & 3.64 \\
\hline NGC 6369 & 098 & - & $1.48^{-4}$ & $3.98^{-4}$ & $4.47^{-5}$ & $5.62^{-6}$ & $1.86^{-6}$ & IIa & 0.00986 & 0.264 & 6.05 \\
\hline NGC 6439 & 123 & - & $2.63^{-4}$ & $6.31^{-4}$ & $1.32^{-4}$ & $1.32^{-5}$ & $1.82^{-6}$ & IIa & 0.0151 & 0.310 & 2.42 \\
\hline NGC 6445 & 110 & - & $2.69^{-4}$ & $7.41^{-4}$ & $8.13^{-5}$ & $1.02^{-5}$ & $2.82^{-6}$ & $\mathrm{IIa}$ & 175 & 0.285 & 6.60 \\
\hline 6543 & 0.110 & $.40^{-4}$ & $6.61^{-5}$ & $5.89^{-4}$ & $1.00^{-4}$ & $1.35^{-5}$ & $2.19^{-6}$ & b & 08 & 287 & 22 \\
\hline NGC 6563 & 0.118 & - & $2.14^{-4}$ & $5.37^{-4}$ & - & - & $1.90^{-6}$ & IIa & 0.0130 & 0.301 & 6.83 \\
\hline NGC 6565 & 0.100 & $4.79^{-4}$ & $2.51^{-4}$ & $5.75^{-4}$ & $7.94^{-5}$ & $1.15^{-5}$ & $2.04^{-6}$ & IIa & 0.0144 & 0.267 & 5.85 \\
\hline NGC 6567 & 102 & $1.10^{-3}$ & $6.03^{-5}$ & $3.80^{-4}$ & $4.90^{-5}$ & $2.87^{-6}$ & $6.61^{-7}$ & IIb & 0.00946 & 0.272 & 4.96 \\
\hline NGC 6572 & 0.100 & $7.24^{-4}$ & $1.32^{-4}$ & $8.71^{-4}$ & $6.17^{-5}$ & $8.32^{-6}$ & $1.95^{-6}$ & IIa & 0.0183 & 0.265 & 5.98 \\
\hline 678 & 02 & - & & $7.76^{-4}$ & $1.55^{-4}$ & $8.91^{-6}$ & $2.24^{-6}$ & a & 83 & 269 & .34 \\
\hline NGC 6629 & 0.087 & - & $4.17^{-5}$ & $4.07^{-4}$ & $4.27^{-5}$ & - & $2.09^{-6}$ & IIb & 0.0101 & 0.241 & 6.08 \\
\hline NGC 6720 & 0.107 & $9.12^{-4}$ & $3.24^{-4}$ & $6.76^{-4}$ & $1.23^{-4}$ & $6.46^{-6}$ & $2.40^{-6}$ & IIa & 99 & 0.279 & 7.60 \\
\hline NGC 6741 & 0.098 & $3.51^{-4}$ & $5.37^{-4}$ & $4.36^{-4}$ & $1.23^{-4}$ & $7.24^{-6}$ & $1.90^{-6}$ & IIa & 0.0152 & 0.262 & 4.46 \\
\hline NGC 6751 & - & - & $1.38^{-4}$ & $7.94^{-4}$ & $1.95^{-4}$ & $1.32^{-5}$ & $2.46^{-6}$ & IIa & & - & 5.64 \\
\hline $\mathrm{No}$ & 107 & - & $1.86^{-4}$ & & & $2.82^{-5}$ & & IIa & 27 & 0.281 & - \\
\hline NGC 6804 & 105 & - & - & $3.31^{-4}$ & $4.36^{-5}$ & - & $1.15^{-6}$ & IIb & 0.00836 & 0.278 & 6.79 \\
\hline NGC 6807 & 105 & - & $8.91^{-5}$ & $4.68^{-4}$ & $6.92^{-5}$ & $7.24^{-6}$ & $1.10^{-6}$ & IIb & 14 & 0.277 & 11.2 \\
\hline NGC 6818 & 105 & $6.31^{-4}$ & $29^{-4}$ & $4.79^{-4}$ & $1.10^{-4}$ & $9.77^{-6}$ & $2.00^{-6}$ & IIa & 0.0137 & 0.277 & 5.08 \\
\hline NGC 6826 & 0.087 & $3.02^{-4}$ & $4.57^{-5}$ & $3.89^{-4}$ & $4.57^{-5}$ & $3.47^{-6}$ & $1.10^{-6}$ & IIb & 85 & 0.241 & 7.78 \\
\hline $\mathrm{NGC}$ & 0.098 & - & $4.27^{-5}$ & $1.10^{-4}$ & $2.00^{-5}$ & $2.00^{-6}$ & $4.90^{-7}$ & IIb & 0.00341 & 0.266 & 9.20 \\
\hline NGC 6853 & 0.112 & $7.94^{-4}$ & $2.29^{-4}$ & $6.46^{-4}$ & $9.12^{-5}$ & $9.55^{-6}$ & $2.04^{-6}$ & IIa & 0.0172 & 0.289 & 7.65 \\
\hline NGC 6881 & 0.102 & - & $2.34^{-4}$ & $4.90^{-4}$ & $6.76^{-5}$ & $1.29^{-5}$ & $2.29^{-6}$ & IIa & 19 & 0.271 & 7.87 \\
\hline NGC 6884 & 0.110 & - & $8.51^{-5}$ & $4.36^{-4}$ & $6.31^{-5}$ & $7.41^{-6}$ & $2.19^{-6}$ & IIb & 0.0107 & 0.287 & 8.29 \\
\hline C 6886 & 096 & - & $2.63^{-4}$ & $4.27^{-4}$ & $1.02^{-4}$ & $9.12^{-6}$ & $3.09^{-6}$ & IIa & 0.0105 & 0.260 & - \\
\hline NGC 6891 & 0.087 & $2.19^{-4}$ & $6.17^{-5}$ & $5.25^{-4}$ & $7.24^{-5}$ & $2.63^{-6}$ & $1.07^{-6}$ & IIb & 0.00989 & 0.241 & 6.62 \\
\hline NGC 6894 & 0.98 & - & $3.39^{-4}$ & $7.59^{-4}$ & $1.32^{-4}$ & $1.74^{-5}$ & $4.47^{-6}$ & IIa & 0.0179 & 0.262 & 7.53 \\
\hline NGC 7009 & 0.110 & $2.29^{-2}$ & $2.14^{-4}$ & $5.37^{-4}$ & $1.02^{-4}$ & $1.35^{-5}$ & $2.14^{-6}$ & IIa & 0.0116 & 0.287 & 6.77 \\
\hline NGC 7026 & 0.110 & - & $3.02^{-4}$ & $6.61^{-4}$ & $1.14^{-4}$ & $2.00^{-5}$ & $3.47^{-6}$ & IIa & 0.0158 & 0.286 & 8.10 \\
\hline NGC 7027 & 0.107 & $7.08^{-2}$ & $1.38^{-4}$ & $3.16^{-4}$ & $7.24^{-5}$ & $6.03^{-6}$ & $1.78^{-6}$ & IIa & 0.0119 & 0.281 & 7.76 \\
\hline NGC 7139 & 125 & - & $1.82^{-4}$ & $3.24^{-4}$ & $5.37^{-5}$ & $1.02^{-5}$ & - & IIa & 0.0082 & 0.316 & 8.17 \\
\hline NGC 7662 & 0.115 & - & $8.91^{-5}$ & $2.63^{-4}$ & $5.89^{-5}$ & $5.01^{-6}$ & $2.57^{-6}$ & IIb & 0.00684 & 0.298 & - \\
\hline IC 351 & 0.091 & - & $3.80^{-5}$ & $3.80^{-4}$ & $5.62^{-5}$ & $9.12^{-6}$ & $1.38^{-6}$ & IIb & 0.0095 & 0.249 & 12.3 \\
\hline IC 418 & - & $6.46^{-4}$ & & $5.13^{-4}$ & $5.00^{-5}$ & $4.27^{-6}$ & $1.23^{-6}$ & IIb & 0.0127 & - & 8.78 \\
\hline IC 1297 & 0.110 & $4.17^{-4}$ & $1.44^{-4}$ & $5.01^{-4}$ & $8.71^{-5}$ & $9.12^{-6}$ & $1.55^{-6}$ & IIa & 0.0118 & 0.287 & 5.54 \\
\hline IC 1747 & 0.110 & - & $1.62^{-4}$ & $5.75^{-4}$ & $8.13^{-5}$ & $8.32^{-6}$ & $1.62^{-6}$ & IIa & 0.0138 & 0.286 & 9.76 \\
\hline IC 2149 & - & $2.19^{-4}$ & $2.29^{-5}$ & $3.39^{-4}$ & $3.02^{-5}$ & $3.16^{-6}$ & $8.91^{-7}$ & IIb & 0.00647 & - & 10.2 \\
\hline IC 2165 & 0.107 & $9.33^{-4}$ & $1.02^{-4}$ & $2.69^{-4}$ & $4.57^{-5}$ & $3.39^{-6}$ & $1.00^{-6}$ & IIa & 0.0124 & 0.281 & 11.4 \\
\hline IC 2448 & 0.100 & - & $8.13^{-5}$ & $3.09^{-4}$ & $4.47^{-5}$ & - & $1.58^{-6}$ & IIb & 0.00787 & 0.268 & 7.61 \\
\hline IC 3568 & 0.091 & $3.80^{-4}$ & $4.57^{-5}$ & $4.17^{-4}$ & $5.25^{-5}$ & $5.25^{-}$ & $7.41^{-7}$ & IIb & 0.0095 & 0.249 & 10.0 \\
\hline
\end{tabular}




\begin{tabular}{|c|c|c|c|c|c|c|c|c|c|c|c|}
\hline 1 & 2 & 3 & 4 & 5 & 6 & 7 & 8 & 9 & 10 & 11 & 12 \\
\hline IC 4191 & .107 & - & $.26^{-2}$ & $5.25^{-}$ & $1.18^{-}$ & $.91^{-}$ & $2.63^{-6}$ & $\mathrm{IIa}$ & .0127 & 0.281 & - \\
\hline IC 4406 & 120 & - & $1.74^{-4}$ & $5.50^{-4}$ & $9.55^{-5}$ & $1.51^{-5}$ & $2.51^{-6}$ & IIa & .0132 & 0.305 & 7.15 \\
\hline IC 4593 & .091 & - & $1.82^{-5}$ & $2.88^{-4}$ & $3.63^{-5}$ & $3.63^{-6}$ & $9.12^{-7}$ & $\mathrm{IIb}$ & 0.00747 & 0.250 & 6.46 \\
\hline IC 4634 & 0.082 & $1.07^{-4}$ & $4.79^{-5}$ & $3.31^{-4}$ & $5.13^{-5}$ & $4.17^{-6}$ & $8.91^{-7}$ & IIb & 0.00632 & 0.230 & 2.88 \\
\hline IC 4776 & - & - & $1.66^{-4}$ & $5.01^{-4}$ & $6.92^{-5}$ & $6.31^{-6}$ & $1.58^{-6}$ & IIa & .0122 & - & - \\
\hline IC 4846 & .087 & $1.70^{-4}$ & $5.01^{-5}$ & $5.37^{-4}$ & $6.02^{-5}$ & $5.00^{-6}$ & $9.77^{-7}$ & IIb & 0.00936 & 0.241 & 3.99 \\
\hline IC 4997 & 0.102 & $1.51^{-4}$ & $6.76^{-5}$ & $2.34^{-4}$ & $2.24^{-5}$ & $9.77^{-6}$ & $1.26^{-6}$ & IIb & 0517 & 0.273 & 7.48 \\
\hline IC 5117 & .091 & - & $1.15^{-4}$ & $3.63^{-4}$ & $5.62^{-5}$ & $8.32^{-6}$ & $1.38^{-6}$ & IIa & 0.00908 & 0.249 & 9.59 \\
\hline IC 5217 & 0.098 & - & $7.94^{-5}$ & $3.55^{-4}$ & $6.03^{-5}$ & $7.08^{-6}$ & $1.38^{-6}$ & IIb & 0.0089 & 0.264 & 3.79 \\
\hline BD 30 & - & - & $10^{-4}$ & $2.00^{-4}$ & $7.76^{-5}$ & $7.59^{-6}$ & $7.24^{-7}$ & IIa & 0.00557 & - & - \\
\hline I 320 & 0.096 & $4.17^{-4}$ & $7.08^{-5}$ & $2.95^{-4}$ & $4.79^{-5}$ & $4.17^{-6}$ & $8.71^{-7}$ & IIb & 0.00871 & 0.260 & 11.0 \\
\hline I 900 & 0.093 & $1.90^{-4}$ & $4.47^{-5}$ & $3.02^{-4}$ & $6.46^{-5}$ & $3.63^{-6}$ & $6.92^{-7}$ & IIb & 664 & 0.254 & 3.8 \\
\hline A 2 & - & - & $9.55^{-5}$ & $3.63^{-4}$ & $8.91^{-5}$ & $7.41^{-6}$ & - & IIb & 910 & - & 9.53 \\
\hline A 4 & 0.081 & - & $1.70^{-4}$ & $3.98^{-4}$ & $5.75^{-5}$ & $5.75^{-6}$ & - & IIa & 0.00987 & 0.227 & 11.1 \\
\hline На 2-1 & - & - & $2.51^{-5}$ & $2.34^{-4}$ & - & $4.07^{-6}$ & $7.08^{-7}$ & IIb & 29 & - & .70 \\
\hline $\mathrm{Hb} 4$ & 0.118 & - & $3.09^{-4}$ & $6.17^{-4}$ & $9.55^{-5}$ & $1.35^{-5}$ & $3.02^{-6}$ & IIa & 0.0148 & 0.301 & 4.12 \\
\hline $\mathrm{He} 2-108$ & 0.107 & - & $3.55^{-5}$ & $1.78^{-4}$ & - & - & - & $11 \mathrm{~b}$ & 507 & 0.283 & 5.84 \\
\hline He 2-131 & - & $2.57^{-4}$ & $2.29^{-4}$ & $7.08^{-4}$ & $1.35^{-4}$ & $9.77^{-6}$ & $2.00^{-6}$ & IIa & 0.0146 & - & 6.47 \\
\hline e $2-138$ & - & - & $2.46^{-4}$ & $8.51^{-4}$ & - & $9.12^{-6}$ & - & IIa & 00 & - & 6.03 \\
\hline He 2 & 112 & - & $37^{-5}$ & -4 & - & $7.59^{-6}$ & $1.55^{-6}$ & IIb & 762 & 292 & 6.49 \\
\hline Нu 2-1 & 0.089 & $3.72^{-4}$ & $3.39^{-5}$ & $2.63^{-4}$ & $4.36^{-5}$ & $3.02^{-6}$ & $1.05^{-6}$ & IIb & 743 & 0.246 & 6.18 \\
\hline $\mathrm{Cu} 2-1$ & 107 & - & $9.12^{-5}$ & $5.10^{-4}$ & $1.51^{-4}$ & $8.13^{-6}$ & $2.40^{-6}$ & IIb & 32 & 0.281 & 4.70 \\
\hline M 1-1 & 0.110 & - & $27^{-5}$ & $1.55^{-4}$ & $3.89^{-5}$ & $4.47^{-6}$ & $7.08^{-4}$ & IIb & 0.00442 & 0.289 & 14.3 \\
\hline M $1-20$ & 0.096 & - & $1.86^{-5}$ & $8.91^{-5}$ & - & $8.51^{-7}$ & $4.90^{-7}$ & II & 0.0 & 0.261 & - \\
\hline M $1-26$ & - & - & -5 & & $1.82^{-4}$ & $1.05^{-5}$ & $2.09^{-6}$ & IIb & 130 & - & 5.49 \\
\hline M 1-27 & - & - & $1.44^{-4}$ & $8.13^{-4}$ & - & $1.38^{-5}$ & - & IIa & 0.0192 & - & 4.57 \\
\hline M 1-56 & 0.110 & - & $9.12^{-5}$ & $3.98^{-4}$ & $4.79^{-5}$ & $1.02^{-5}$ & $2.19^{-6}$ & IIb & 0.00987 & 0.287 & - \\
\hline M 1-61 & 0.107 & - & $15^{-4}$ & $4.36^{-4}$ & $3.80^{-5}$ & $6.76^{-6}$ & $2.09^{-6}$ & IIa & 0.0107 & 0.282 & 2.67 \\
\hline M $1-72$ & - & - & $2.82^{-5}$ & $1.10^{-4}$ & - & $2.82^{-6}$ & $6.92^{-7}$ & IIb & 0.00341 & - & 12.8 \\
\hline M 2-23 & 0.102 & - & $3^{-5}$ & $2.95^{-4}$ & $2.51^{-5}$ & $4.17^{-6}$ & $1.10^{-6}$ & $11 \mathrm{~b}$ & 0.00762 & 0.272 & - \\
\hline M 2-51 & 0.118 & - & $2.46^{-4}$ & $4.57^{-4}$ & $6.31^{-5}$ & - & - & IIa & 0.0112 & 0.302 & 8.65 \\
\hline M 3-1 & 0.098 & - & $4.17^{-5}$ & $2.75^{-4}$ & $2.82^{-5}$ & $9.77^{-6}$ & $1.29^{-6}$ & IIb & 0.00710 & 0.265 & 12.2 \\
\hline M 4-18 & - & - & $6.76^{-5}$ & $4.90^{-4}$ & $5.25^{-5}$ & - & . & IIb & 0.0119 & - & 12.6 \\
\hline $\mathrm{Pb} 4$ & 0.115 & - & $8.13^{-5}$ & $3.80^{-4}$ & $5.75^{-5}$ & $5.62^{-6}$ & $2.34^{-6}$ & $\mathrm{IIb}$ & 0.00946 & 0.297 & 8.59 \\
\hline Tc 1 & 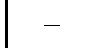 & $.71^{-4}$ & & & $8.51^{-5}$ & $4.57^{-6}$ & $1.66^{-6}$ & IIb & 0.0161 & - & 5.55 \\
\hline K 1-7 & 0.120 & - & $1.58^{-4}$ & $3.80^{-}$ & $5.01^{-!}$ & $6.31^{-6}$ & - & $\mathrm{IIa}$ & 0.00946 & 0.306 & 11.6 \\
\hline
\end{tabular}

Table 1. Chemical composition and basic parameters of the type II planetary nebulae.

\section{ANALYSIS OF $Y-Z$ DIAGRAM AND \\ DETERMINATION OF THE RADIAL ABUNDANCE GRADIENTS IN THE GALACTIC DISK}

The helium abundance in the PNs can be written as

$$
Y=Y_{p}+(d Y / d Z) Z+\Delta Y_{s}
$$

where $Y$ and $Z$ are the mass fractions of helium and heavy elements, respectively. Here $\Delta Y_{s}$ represents the star's contribution to the He abundance in the PN. This value is in the range $0.008<\Delta Y_{s}<0.022$ [7], depending on the mass of a star. For our calculations, we assume that the mean value is $\Delta Y_{s}=0.015$.

Provided that $X, Y$ and $Z$ are the mass fractions of hydrogen, helium and heavy elements, respectively, we can note

$$
X+Y+Z=1
$$

then

$$
\begin{aligned}
& X=\frac{X}{X+Y+Z}, \\
& Y=\frac{Y}{X+Y+Z}, \\
& Z=\frac{Z}{X+Y+Z},
\end{aligned}
$$

Or

$$
X=\frac{1}{1+Y / H+Z / H},
$$




$$
\begin{aligned}
& Y=\frac{Y / X}{1+Y / H+Z / H}, \\
& Z=\frac{Z / H}{1+Y / H+Z / H} .
\end{aligned}
$$

It is well known that $Y=4 \mathrm{He} / \mathrm{H}$, similarly

$$
Z=\frac{Z_{a}}{1+4 \mathrm{He} / \mathrm{H}+Z_{a}}
$$

where

$$
Z_{a} \approx 12 \frac{\mathrm{C}}{\mathrm{H}}+14 \frac{\mathrm{N}}{\mathrm{H}}+16 \frac{\mathrm{O}}{\mathrm{H}}+20 \frac{\mathrm{Ne}}{\mathrm{H}}+32 \frac{\mathrm{S}}{\mathrm{H}}+40 \frac{\mathrm{Ar}}{\mathrm{H}} .
$$

Thus, we have

$$
\begin{aligned}
& X=\frac{1}{1+4 \mathrm{He} / \mathrm{H}+Z_{a}}, \\
& Y=\frac{4 H e / H}{1+4 \mathrm{He} / \mathrm{H}+Z_{a}}, \\
& Z=\frac{Z_{a}}{1+4 \mathrm{He} / \mathrm{H}+Z_{a}} .
\end{aligned}
$$

Finally, parameters $Y$ and $Z$ are given by

$$
Y=\frac{4 \mathrm{He} / \mathrm{H}(1-Z)}{1+4 \mathrm{He} / \mathrm{H}}, \quad Z=\frac{Z_{a}}{1+4 \mathrm{He} / \mathrm{H}+Z_{a}} .
$$

The parameter $Z_{a}$ is not known for all PNs (C is unobservable). Therefore, in order to compute $Z$ we have considered the dependence between $Z(\mathrm{C}, \mathrm{N}, \mathrm{O}, \mathrm{Ne}, \mathrm{S}$, Ar) and $\mathrm{O} / \mathrm{H}$ (Fig. 2):

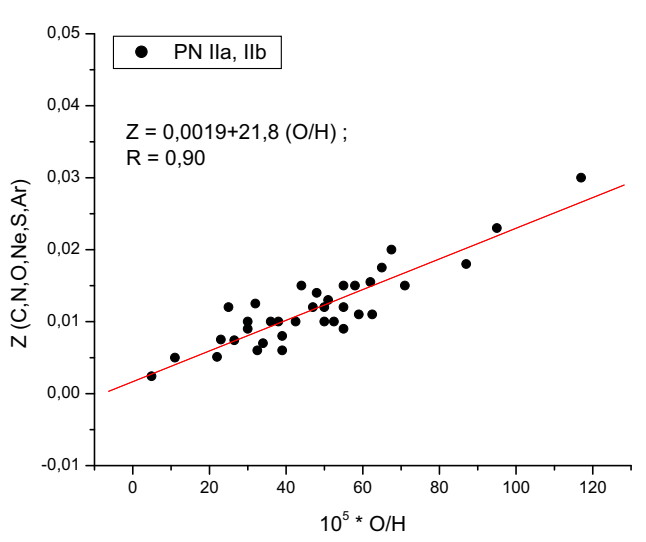

Fig. 2. Relation between $Z$ and $\mathrm{O} / \mathrm{H}$ for the type II PNs.

$$
Z=21.8 \frac{O}{H}+0.0019 \quad(R=0.90 ; n=37)
$$

for the type IIa,b PNs. Here presented are also the correlation coefficient $(R)$ and the number of points $(n)$.

The parameters $Y$ and $Z$ for the IIa,b type PNs obtained by this method are listed in Table 1 in columns 10 and 11.

In order to determine the primordial helium abundance $Y_{p}$ and the helium-to-metal enrichment ratio $d Y / d Z$, we have used samples of the type IIa,b PNs (our data) in conjuction with the HII regions in the blue compact dwarf galaxies (HII in BCDG) [8]. $Y-Z$ diagrams for all of these samples are built. In Fig. 3 the relationship between $Y$ and $Z$ for the type IIa, IIb PNs (our data, see Table. 1) and the HII regions in BCDG [8] is shown. The correlation coefficient $(R)$ and the standard deviation (SD) also are presented.

The obtained values of the parameters $Y_{p}$ and $d Y / d Z$ from all the $Y-Z$ diagrams are as follows:

\begin{tabular}{|c|c|c|c|c|}
\hline$Y_{p}$ & $\Delta Y_{p}$ & $d Y / d Z$ & $\Delta(d Y / d Z)$ & \\
\hline 0.247 & 0.006 & 2.85 & 0.49 & for Type IIa PNs \\
\hline 0.235 & 0.009 & 4.02 & 1.08 & for Type IIb PNs \\
\hline 0.243 & 0.004 & 3.18 & 0.37 & for Type IIa,b PNs \\
\hline 0.246 & 0.002 & 2.91 & 0.21 & for Type IIa,b PNs and HII in BCDG \\
\hline
\end{tabular}

Table 2.

We should note that the standard deviations for all of these dependences are nearly 0.01 .

In order to determine the radial abundance gradients in the galactic disk $d A / d D$, we have selected a subsample containing the type II galactic PNs, for which accu- rate abundances and distances $[9,10]$ are available (Table 1). The distance to the center of the Galaxy was assumed to be $R_{0}=7.8 \mathrm{kpc}$ [11]. The following leastsquare approximations have been obtained for the dependences of $\log (A / \mathrm{H})+12$ on the galactocentric dis- 


\section{V. HOLOVATYY, N. V. HAVRYLOVA}

tance $D$ (Fig. 4, 5), where the standard deviations (SD) and the number of points $(n)$ for every dependence are given in parentheses:

\begin{tabular}{|l|l|}
\hline $\mathrm{He} / \mathrm{H}=-0.0014 \times D+0.12$ & $(S D=0.01, n=51)$ \\
\hline $\mathrm{N} / \mathrm{H}=-0.0040 \times D+8.31$ & $(S D=0.31, n=55)$ \\
\hline $\mathrm{O} / \mathrm{H}=-0.0368 \times D+8.91$ & $(S D=0.22, n=55)$ \\
\hline $\mathrm{Ne} / \mathrm{H}=-0.0367 \times D+8.12$ & $(S D=0.22, n=52)$ \\
\hline $\mathrm{S} / \mathrm{H}=-0.0173 \times D+7.02$ & $(S D=0.13, n=51)$ \\
\hline $\mathrm{Ar} / \mathrm{H}=-0.0399 \times D+6.49$ & $(S D=0.20, n=54)$ \\
\hline
\end{tabular}

Table 3.

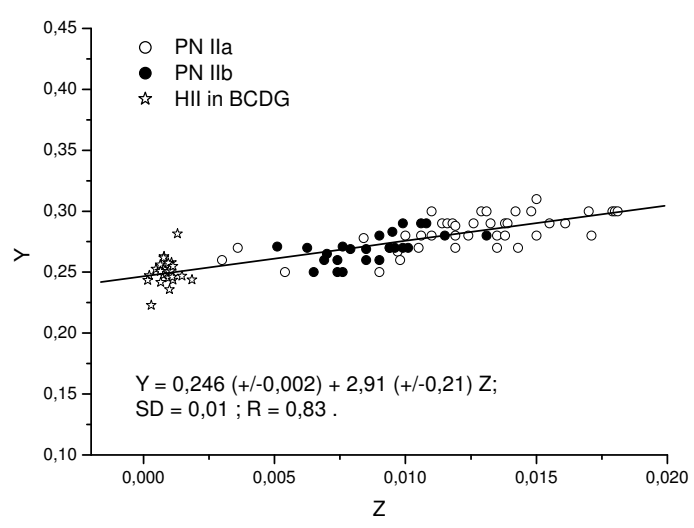

Fig. 3. Relation $Y-Z$ for the type Ila,b PNs and the HII regions in $\mathrm{BCDG}$.

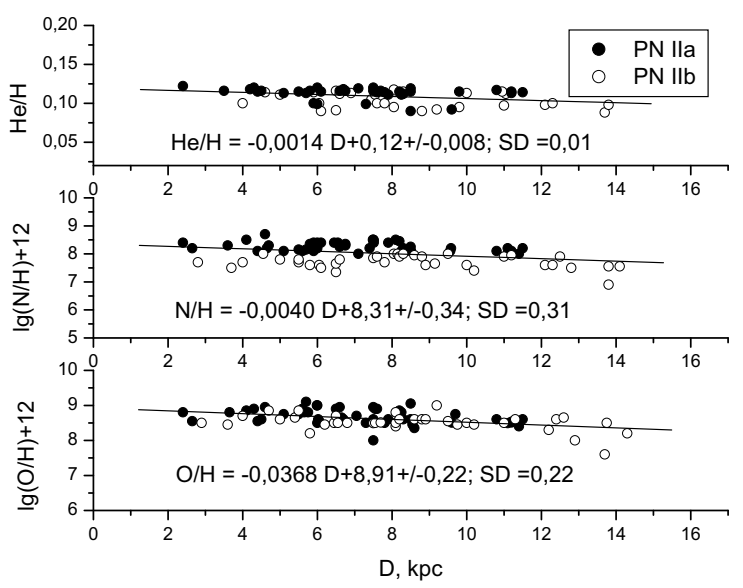

Fig. 4. The radial abundance gradients in the galactic disk for He, N, O.

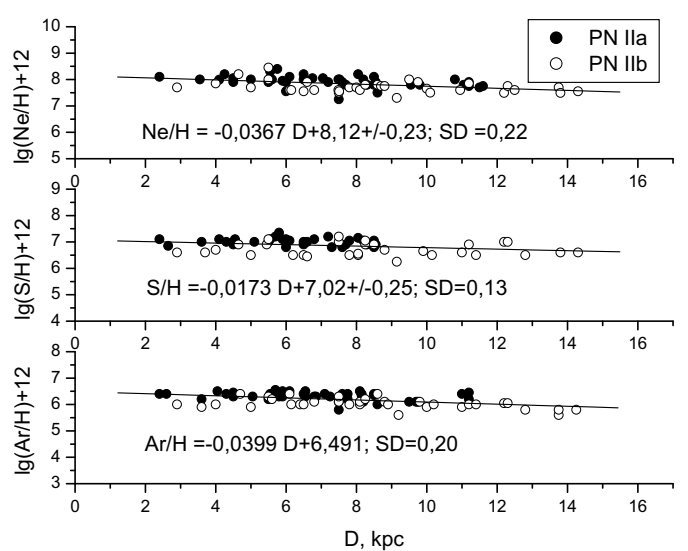

Fig. 5. The radial abundance gradients in the galactic disk for Ne, S, Ar.

Here we point out that our data somewhat differ from the corresponding data of Maciel and Köppen (1994) [6]. We believe that these differences can be explained by differences in the chemical abundances and the distance scales to PNs.

\section{CONCLUDING REMARKS}

We have determined the chemical composition of PNs with the radial distribution of gas density derived by Golovatyi et al. [1]. In contrast to other authors, we use this density distribution because it is closer to the real one. The data of the chemical composition of 200 galactic planetary nebulae are determined. The abundances of He, C, N, O, Ne, Mg, Si, S, and Ar are found for 175 , 64, 190, 200, 170, 13, 40, 173 and $187 \mathrm{PNs}$, respectively. The abundances for all PNs are obtained using the same atomic data and the same method of abundance determination.

The radial abundance gradients in the galactic disk $d A / d D$ for He, N, O, Ne, S and Ar are determined. They differ somewhat from, for example, the corresponding data by Maciel and Köppen [6]. We believe that these differences can be explained by the differences between chemical abundances obtained by our method and other ones, as well as by the adopted distance scales to planetary nebulae $[9,10]$.

For a sample of $86 \mathrm{PNs}$ of the IIa,b types, parameters $Y$ and $Z$ are calculated, using the dependence of $Z$ (C, $\mathrm{N}, \mathrm{O}, \mathrm{Ne}, \mathrm{S}, \mathrm{Ar}$ ) on $\mathrm{O} / \mathrm{H}$. From the relation $Y-Z$, the primordial helium abundance $Y_{p}$ and the enrichment ratio $d Y / d Z$ are obtained for the different PNs type combinations and in conjuction with the corresponding data for the HII regions in BCDG [8]. We note that PNs contain more helium when compared to the HII regions, because He can be produced in stars of medium masses. Though we assume $Y_{p}=0.246( \pm 0.002)$, this result needs further correction. 


\title{
ACKNOWLEDGEMENTS
}

It is our pleasure to thank Dr. G. Stasinska for her comments on this work. This study has been financially supported by the ESO C\&EE Grant A-07-006.

[1] V. V. Golovatyi, V. L. Dmiterko, Yu. F. Mal'kov, O. V. Rokach, Astron. Rep. 37, 346 (1993).

[2] D. Schönberner, Astron. Astrophys. 79, 108 (1979).

[3] D. Schönberner, Astrophys. J. 272, 708 (1983).

[4] B. Paczynski, Acta Astron. 21, 417 (1971).

[5] R. E. S. Clegg, D. Middlemass, Mon. Not. R. Astron. Soc. 228, 759 (1987).

[6] W. J. Maciel, J. Köppen, Astron. Astrophys. 282, 436
(1994).

[7] C. Chippiani, W. J. Maciel, Astron. Astrophys. 288, 921 (1994).

[8] V. V. Golovatyi, B. Ya. Melekh, Astron. Rep. 46, N10, 779 (2002).

[9] Yu. F. Malkov, Astron. Zh. 74, 853 (1997).

[10] Yu. F. Malkov, Astron. Zh. 75, 334 (1998).

[11] R. Racine, W. E. Harris, Astron. Zh. 98, 1609 (1989).

\section{ХЕМІЧНИЙ УМІСТ ГАЛАКТИЧНИХ ПЛАНЕТАРНИХ ТУМАННОСТЕЙ \\ В. В. Головатий ${ }^{1}$, Н. В. Гаврилова ${ }^{2}$ \\ ${ }^{1}$ Львівсъкий начіональний університет імені Івана Франка, кафедра астрофізики вул. Кирила і Мефоділ, 8, 79005, Львів, Украйна \\ 2 Львібсъкий начіональний університет імені Івана Франка, астрономічна обсерваторіл вул. Кирила і Мефодія, 8, 79005, Львів, Украӥна}

\begin{abstract}
Розпочато вивчення хемічного вмісту планетарних туманностей з урахуванням різноманітних типів неоднорідностей густини газу в їхніх оболонках. Використовуючи близький до реального радіяльний розподіл густини газу, визначено хемічний уміст 200 галактичних планетарних туманностей. Знайдено вмісти Не, C, N, O, Ne, Mg, Si, S та Ar відповідно для 175, 64, 190, 200, 170, 13, 40, 173 та 187 об'єктів. Умісти для всіх планетарних туманностей та вмісти фотойонізаційних моделей для розрахунку йонізаційно-корекційних факторів знайдено з використанням одного методу та однакових атомних даних. Дані спостережень зібрано зі 105 джерел, опублікованих раніше. Проаналізовано діяграми $Y-Z$ для планетарних туманностей IІа,b типів у поєднанні з даними для НІІ ділянок у блакитних компактних карликових галактиках. Використавши залежність між $Y$ та $Z$, обчислено догалактичний уміст гелію $Y_{p}$ та величину збагачення важкими елементами $d Y / d Z$. Знайдено радіяльні градієнти вмістів у Галактичному диску для Не, N, O, Ne, S та Ar. Показано, що знайдені градієнти цих елементів дещо нижчі порівняно з відповідними даними інших авторів.
\end{abstract}

